\title{
The Effect of Education on Clinical Practice Guidelines with Shared Decision Making: A Randomized Controlled trial
}

Shuhei Fujimoto ( $\nabla$ shuheifujimototbr@gmail.com )

Kyoto University Graduate School of Medicine https://orcid.org/0000-0001-8031-0604

Tatsuya Ogawa

Kio University Graduate School of Health Science

Kanako Komukai

Wellness Frontier Co., Ltd

Takeo Nakayama

Kyoto University Graduate School of Medicine

\section{Research article}

Keywords: Evidence based medicine, Communication skill, Rehabilitation

Posted Date: August 19th, 2020

DOI: https://doi.org/10.21203/rs.3.rs-52479/v1

License: (1) This work is licensed under a Creative Commons Attribution 4.0 International License. Read Full License 


\section{Abstract}

Background: To investigate the influence of the evidence-practice gap on physiotherapists and occupational therapists through shared decision making (SDM) education using clinical practice guidelines (CPGs).

Methods: The study design was a multicenter, blocked, randomized control trial. Participants included 126 therapists with 42 continuous samplings from the three institutions. Inclusion criteria were being a permanent employee from the institutions. Exclusion criteria were participants with disorders that may cause intervention (visual, auditory, attentional disorder).

An allocator assigned masked the participation's attribution until the allocation was completed. The evaluator and analyzer were masked.

For the intervention group, workshop on SDM using the CPGs were conducted. The control group was lecture on the knowledge of CPGs (CPG group) and lecture on the knowledge of SDM (SDM group).

The primary outcomes were education, attitudes and beliefs, and interest and perceived role in evidence-based practice (EPIC scale). The secondary outcome was the Evidence based practice (EBP) knowledge. To review the intervention effect of the education on SDM using CPGs, two-factor variance analysis (mixed model) was adopted to conduct Holm's method in comparison to a post-hoc test.

Results: Participants randomized and analysed in each group were 42. The EPIC scale showed significant difference between CPGs

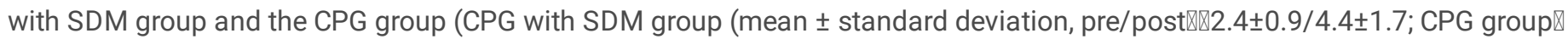
$3.0 \pm 1.5 / 3.5 \pm 2.0$; SDM group $\varangle 2.6 \pm 1.2 / 3.3 \pm 1.8 \bigotimes$. The question item on EBP "I learned the foundations for EBP as part of my academic

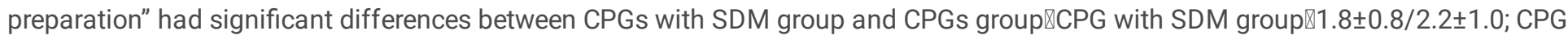
group $\otimes 2.3 \pm 1.1 / 2.0 \pm 1.0 \otimes$.

Conclusions: EBP education on the SDM using CPGs increased confidence in using EBP for physiotherapists and occupational therapists.

\section{Background}

Evidence-based practice (EBP) is defined as: providing medical care with the integration of evidence from clinical study, clinical expertise, and patient value [1]. Self-efficacy in knowledge, skills, and attitudes is essential in actual practice [2-4]. Hence, the demand for EBP education in rehabilitation professions is pointed out $[5,6]$.

In EBP education, the knowledge of clinical practice guidelines (CPGs) is thought to increase the self-efficacy of EBP [7-9]. Moreover, the relevance of the knowledge/attitude of CPGs and self-efficacy in EBP is reported frequently [10-12]. A CPG is defined as: "...a document that presents appropriate recommendations to assist patients and practitioners in making rescissions regarding clinical practice of high importance based on the body of evidence evaluated and integrated by systematic reviews and the balance between benefits and harms [13]." CPGs are proven to be functional as a tool to support the decision-making of medical practitioners in clinical practice [14].

On the other hand, the fundamental communication skill in conducting EBP is shared decision making (SDM) [15-17]. SDM is a practice method that prevents patients and medical practitioners from experiencing perception gaps in clinical practice [18]. Cooperating with SDM in integrating the three elements of EBP evidence, clinical expertise, and patients' perspectives is essential in the decision-making process. The educational effect of SDM is suggested to increase self-efficacy in EBP, especially for evidence selection and taking in patients' perspectives [19-23].

However, the method for cooperating with the knowledge/attitude of CPGs for patient communication in clinical practice is not systematized. It is assumed that concurrently conducting SDM education in CPG education could greatly increase the self-efficacy of EBP.

The purpose of this study was to investigate the influence of the evidence-practice gap on physiotherapists and occupational therapists through the novel educational methods conducting SDM education using CPGs. 


\section{Methods}

Study design and participants

This study was registered in University Hospital Medical Information Network center (ID: UMIN000035448), and this report depended on Consolidated Standards of Reporting Trials (CONSORT) [24].

This study was conducted with the approval of the Ever Walk Inc. Research Ethics Committee (Authorization No.: 002) . Respondents were informed about the project and they provided written consent to participate.

The design for this study was a multicenter, randomized control trial. Participants included 126 therapists (physio and occupational), with 42 continuous samplings from each of the three institutions (allocation ratio: 1:1). The setting was Japanese medical institutions. After the researchers explained the research content, participants agreed in writing. Considering the measurement bias of the subjects, the research hypothesis was not explained.

Inclusion criteria were: 1) being a permanent employee from one of the institutions, 2) those who were employed full-time, and 3) those who agreed to participate in the research. Exclusion criteria were: participants with disorders that may cause intervention in the research, such as visual, auditory, attentional disorder, etc. The existence of the disorders relating to the exclusion criteria relied on self-certification.

Although there was no declination from the protocol, changes were made to the designed randomization in conducting the research. As shown below, block randomization was adopted while taking into consideration the characteristic variation of the research institutions, whereas block randomization was not adopted in the study protocol.

Randomization and blinding

Block randomization was implemented, in which random allocation was divided by affiliation (three block sizes). The sealed envelope system in central registration was used for allocation. This was enacted during the phase when the principal investigator finished selecting the research subjects. Forty-two subjects from each institution were allocated into three groups, with each group having 14 subjects. The allocation was conducted in the order of enrollment in each institution. The allocator was assigned as an intervenient conducting the educational program. The target's attribution, other than their affiliation, was masked to the allocators until the allocation was completed.

The results of the allocation were known only by the intervenient of the educational program, and the targets were informed after the study was completed. It was arranged so that the contrasting allocating educational program was available if desired.

The outcome evaluator and the analyzer were masked. Analysis was undertaken by members who were not involved in the assessment allocation or conduction of the educational program. Results of the acquired outcomes were concealed to other research collaborators until analysis was completed.

Interventions

For the intervention group, 2 hours of workshop and lecture on SDM using CPGs were conducted (CPG with SDM group). The control group was divided into two groups: one with 2 hours of lecture on the knowledge of CPGs (CPG group) and one with a lecture on the knowledge of SDM (SDM group).

The workshop on SDM using CPGs was conducted in three compositions. The first workshop worked in pairs. The task was to verbally guide the blinded partner to a destination without touching them. The aim of this workshop was to understand the difficulty and to learn the method in explaining the information verbally. 
The second workshop was to practice explaining whether Fruit A or Fruit B was good for health. Afterward, subjects studied the elements to effectively explain the benefits along the nine-steps of SDM [25]. The nine-steps of SDM is a technique used whereby medical practitioners and patients cooperate in decision-making. It is constructed from the following steps: 1. Disclosure that a decision needs to be made, 2. Formulation of the equality of partners, 3. Presentation of treatment options, 4. Informing on the benefits and risks of the options, 5 . Investigation of the patients' understanding and expectations, 6 . Reaching a shared decision, and 9. Arrangement of follow-ups [25].

The third workshop assumed a case in improving the walking speed of a stroke patient. In this workshop, the subjects actually arranged a CPG and evidence according to the patients' goal through the nine-steps of SDM. This was conducted in a group of 5-6 members.

For the lecture on the knowledge of the $\mathrm{CPG}$, the following contents were included: the definition of CPGs, process of the creation of the $\mathrm{CPG}$, evaluation method of the systematic review and the risk of bias, and the evaluation of the CPG approach in evaluating the CPG.

The lecture on the knowledge of SDM included the definition of SDM and its difference from informed consent, the summary of the nine-steps of SDM [25], and the process of decision-making.

\section{Outcomes}

Education, attitudes and beliefs, and interest and perceived role in evidence-based practice (EPIC scale) [26] was used for the primary outcomes (S1 Table). The EPIC scale is a self-administered questionnaire that evaluates the degree of self-efficacy at 11 levels. For the secondary outcome, an examination of the knowledge of EBP [27-30] was conducted (Table S2). The knowledge of the EBP was evaluated using a questionnaire survey composed of 15 items on attitudes toward EBP, EBP education, and EBP-associated behaviors. A Likert scale (answers of three selections: "Agree," "Neither agree nor disagree," and "Disagree" and five selections: from "Strongly agree" to "Strongly disagree") was used for answers.

Sample size

The calculation of the sample size was performed based on the results of the 30 participants who were primarily tested: effect size $f=0.14$, a error $=0.05$, and power $=0.8$. $G$ power was used to calculate the sample size.

Termination of the trial

The trial was terminated by the judgement of the principal investigator and the research collaborator if: the number of participants did not meet the prescribed number, a participant dropped out due to an unintentional reason, failure to meet the target number, or if it was judged to be disadvantageous for the subjects. The termination of the study was to be noted in writing to the participants, reporting the facts known at the point of termination. Analysis was conducted using intention to treat analysis.

\section{Confounders}

From the preceding study, the following were recruited as confounding factors: age [10,11], sex, academic history [31] , years of experience [10], acquirement of certified physio/occupational therapist [12], principal disease stage of the hospital employed (acute phase, recovery phase, chronic phase) [10,11], mainly responsible disorder (orthopedic disease, developmental disorder, sports injury, spinal cord injury, post-amputation, psychiatric disorder, neuromuscular disorder, cerebrovascular disease, respiratory disease, cardiovascular disease, and other) [10,11], weekly duty hours [10,11], number of therapists at the hospital employed [10,11], number of hospital beds at the hospital employed [32], number of responsible patients in a day [10,11], and participation in research 
activities[12]. The factors above were inquired through a self-administered questionnaire. An envelope was used to collect the questionnaire to anonymize the individuals.

Statistical analysis

A significance test of the three groups was conducted to review the intervention effect of the workshop and lecture on SDM using CPGs. For the EPIC scale, a significance test was conducted per participant, calculating the mean before and after the intervention. For statistical analysis, since all three groups were evaluated before and after the intervention, two-factor variance analysis (mixed model) was adopted to conduct Holm's method in comparison to the post-hoc test. Likewise, if a significant difference in the confounding factor was recognized, the factor was considered a covariate. All statistical analyses were conducted using R (CRAN) (significance level<0.05).

\section{Results}

The participant selection is shown in the flowchart in Fig. 1. The number of participants randomized to each group were 42. The application period for the participants was from May 1, 2017, to April 30,2018. There were no dropouts or untraceable participants in any groups.

Patient attribution is shown in Table 1.There were no significant differences between each group. 
Table 1

Patient attribution

\begin{tabular}{|c|c|c|c|c|}
\hline & & $\begin{array}{l}\text { CPG with } \\
\text { SDM } \\
(\mathrm{N}=42)\end{array}$ & $\begin{array}{l}\text { CPG } \\
(\mathrm{N}=42)\end{array}$ & $\begin{array}{l}\text { SDM } \\
(N=42)\end{array}$ \\
\hline \multirow[t]{2}{*}{$\operatorname{Sex}(N)$} & Male & 31 & 34 & 26 \\
\hline & Female & 11 & 8 & 16 \\
\hline Age & Mean (SD) & $28.1(4.2)$ & $27.3(6.2)$ & $28.6(5.2)$ \\
\hline \multirow[t]{6}{*}{ Academic history $(\mathrm{N})$} & $\begin{array}{l}\text { Three-year professional school } \\
\text { graduate }\end{array}$ & 8 & 14 & 10 \\
\hline & $\begin{array}{l}\text { Four-year professional school } \\
\text { graduate }\end{array}$ & 20 & 19 & 14 \\
\hline & Junior college graduate & 3 & 3 & 2 \\
\hline & College graduate & 11 & 6 & 16 \\
\hline & Master's degree & 0 & 0 & 0 \\
\hline & Doctoral degree & 0 & 0 & 0 \\
\hline Years of experience & Mean (SD) & $6.1(4.2)$ & $5.4(5.7)$ & $6.3(4.5)$ \\
\hline \multirow[t]{3}{*}{ License (N) } & None & 40 & 41 & 40 \\
\hline & Certified PT/OT & 2 & 1 & 2 \\
\hline & Specialized PT/OT & 0 & 0 & 0 \\
\hline \multirow{4}{*}{$\begin{array}{l}\text { Principal disease stage of the hospital } \\
\text { employed (N) }\end{array}$} & Acute & 21 & 19 & 21 \\
\hline & Subacute & 1 & 0 & 2 \\
\hline & $\begin{array}{l}\text { Maintenance (including } \\
\text { outpatient) }\end{array}$ & 18 & 16 & 15 \\
\hline & Others & 2 & 7 & 4 \\
\hline \multirow[t]{11}{*}{ Mainly responsible disorder $(\mathrm{N})$} & Orthopedic disease & 10 & 6 & 8 \\
\hline & Developmental disorder & 0 & 0 & 0 \\
\hline & Sports disorder & 0 & 0 & 0 \\
\hline & Spinal cord injury & 4 & 0 & 1 \\
\hline & Post-amputation & 0 & 0 & 0 \\
\hline & Psychiatric disorder & 0 & 0 & 0 \\
\hline & Neuromuscular disorder & 1 & 0 & 2 \\
\hline & Cerebrovascular disease & 27 & 30 & 29 \\
\hline & Respiratory disease & 0 & 2 & 2 \\
\hline & Cardiovascular disease & 0 & 4 & 0 \\
\hline & Others & 0 & 0 & 0 \\
\hline \multirow[t]{2}{*}{ Employment status (N) } & Full-time & 42 & 42 & 42 \\
\hline & Part-time & 0 & 0 & 0 \\
\hline Weekly duty hours & Mean (SD) & $40.0(0.0)$ & $41.8(5.3)$ & $40.5(2.6)$ \\
\hline Number of PT/OT at the hospital employed & $<3$ therapists & 0 & 0 & 0 \\
\hline
\end{tabular}

Page 6/15 


\begin{tabular}{|c|c|c|c|c|}
\hline & & $\begin{array}{l}\text { CPG with } \\
\text { SDM } \\
(\mathrm{N}=42)\end{array}$ & $\begin{array}{l}\text { CPG } \\
(\mathrm{N}=42)\end{array}$ & $\begin{array}{l}\text { SDM } \\
(N=42)\end{array}$ \\
\hline \multirow[t]{4}{*}{$(\mathrm{N})$} & $3-5$ therapists & 3 & 3 & 2 \\
\hline & $6-10$ therapists & 2 & 5 & 5 \\
\hline & $11-15$ therapists & 7 & 10 & 7 \\
\hline & $>16$ therapists & 30 & 24 & 28 \\
\hline $\begin{array}{l}\text { Number of hospital beds at the hospital } \\
\text { employed }\end{array}$ & & $164.4(69.5)$ & $134.2(81.9)$ & 149.8(100.7) \\
\hline \multirow[t]{4}{*}{ Number of responsible patients in a day } & $1-10$ patients & 17 & 24 & 18 \\
\hline & $11-15$ patients & 25 & 14 & 23 \\
\hline & $>16$ patients & 0 & 4 & 1 \\
\hline & None & 0 & 0 & 0 \\
\hline \multirow[t]{3}{*}{ Participation in research activities $(\mathrm{N})$} & Yes & 0 & 0 & 0 \\
\hline & Partially & 6 & 9 & 12 \\
\hline & Not at all & 36 & 33 & 30 \\
\hline \multicolumn{5}{|l|}{ SDM: Shared decision making } \\
\hline \multicolumn{5}{|l|}{ CPG: Clinical practice guideline } \\
\hline \multicolumn{5}{|l|}{ PT: Physical therapist } \\
\hline \multicolumn{5}{|l|}{ OT: Occupational therapist } \\
\hline SD: Standard deviation & & & & \\
\hline
\end{tabular}

The results of the EPIC scale are shown in Table 2. The mean value for each group was significant differences between the CPG with SDM group, SDM group, and CPG group. (CPG with SDM group (mean \pm standard deviation; pre/post): $2.4 \pm 0.9 / 4.4 \pm 1.7$, CPG group: $3.0 \pm 1.5 / 3.5 \pm 2.5$, SDM group: $2.6 \pm 1.2 / 3.3 \pm 1.8)$. 
Results of EPIC scale

\begin{tabular}{|c|c|c|c|c|c|c|c|c|c|c|c|c|c|c|c|c|c|c|c|c|}
\hline \multirow{4}{*}{$\begin{array}{l}\text { EPIC } \\
\text { scale }\end{array}$} & \multirow{3}{*}{$\begin{array}{l}\text { No. } \\
1\end{array}$} & \multicolumn{6}{|c|}{ CPG with SDM Group $(N=42)$} & \multicolumn{6}{|c|}{ CPG Group $(\mathrm{N}=42)$} & \multicolumn{7}{|c|}{ SDM Group $(N=42)$} \\
\hline & & \multicolumn{2}{|l|}{ Pre } & \multicolumn{4}{|c|}{ Post } & \multicolumn{3}{|l|}{ Pre } & \multicolumn{3}{|l|}{ Post } & \multicolumn{3}{|l|}{ Pre } & \multicolumn{4}{|c|}{ Post } \\
\hline & & 2.4 & \pm & 1.4 & 4.3 & \pm & 2.2 & 3.6 & \pm & 2.1 & 3.7 & \pm & 2.0 & 2.8 & \pm & 1.8 & 3.5 & \pm & 1.8 & \\
\hline & 2 & 2.7 & \pm & 1.1 & 4.1 & \pm & 1.7 & 2.8 & \pm & 1.7 & 2.9 & \pm & 1.8 & 2.9 & \pm & 1.4 & 3.0 & \pm & 1.7 & \\
\hline & 3 & 3.2 & \pm & 1.7 & 4.6 & \pm & 1.4 & 3.3 & \pm & 2.0 & 3.8 & \pm & 2.1 & 3.0 & \pm & 1.7 & 3.6 & \pm & 1.7 & *十 \\
\hline & 4 & 2.6 & \pm & 1.1 & 2.9 & \pm & 1.6 & 2.6 & \pm & 1.8 & 2.5 & \pm & 1.8 & 2.6 & \pm & 1.6 & 2.3 & \pm & 1.3 & \\
\hline & 5 & 2.0 & \pm & 1.4 & 3.5 & \pm & 1.7 & 2.6 & \pm & 1.4 & 2.6 & \pm & 1.6 & 2.1 & \pm & 1.7 & 2.6 & \pm & 1.5 & \\
\hline & 6 & 2.0 & \pm & 1.2 & 1.7 & \pm & 1.5 & 1.5 & \pm & 2.0 & 1.2 & \pm & 2.0 & 1.5 & \pm & 1.6 & 1.1 & \pm & 1.6 & \\
\hline & 7 & 1.7 & \pm & 1.4 & 1.4 & \pm & 1.3 & 1.1 & \pm & 1.6 & 0.9 & \pm & 1.8 & 1.4 & \pm & 1.2 & 0.8 & \pm & 1.3 & \\
\hline & 8 & 2.0 & \pm & 1.2 & 3.5 & \pm & 1.6 & 3.3 & \pm & 1.7 & 3.1 & \pm & 1.8 & 2.6 & \pm & 1.7 & 2.8 & \pm & 1.7 & * \\
\hline & 9 & 2.3 & \pm & 1.2 & 5.0 & \pm & 2.1 & 4.5 & \pm & 2.3 & 4.0 & \pm & 1.6 & 3.6 & \pm & 1.9 & 3.9 & \pm & 1.7 & *十 \\
\hline & 10 & 2.4 & \pm & 1.2 & 4.4 & \pm & 1.9 & 3.7 & \pm & 2.2 & 3.0 & \pm & 1.9 & 3.0 & \pm & 1.8 & 3.4 & \pm & 1.7 & *十 \\
\hline & 11 & 2.7 & \pm & 1.4 & 4.4 & \pm & 1.7 & 3.5 & \pm & 2.1 & 3.5 & \pm & 2.0 & 2.8 & \pm & 1.8 & 3.3 & \pm & 1.8 & $t$ \\
\hline & Mean & 2.4 & \pm & 0.9 & 4.4 & \pm & 1.7 & 3.0 & \pm & 1.5 & 3.5 & \pm & 2.0 & 2.6 & \pm & 1.2 & 3.3 & \pm & 1.8 & $* \dagger$ \\
\hline \multicolumn{21}{|c|}{ SDM: Shared decision making } \\
\hline \multicolumn{21}{|c|}{ CPG: Clinical practice guideline } \\
\hline \multicolumn{21}{|c|}{ * CPG with SDM group vs. CPG group: $p<0.05$} \\
\hline \multicolumn{21}{|c|}{ †CPG with SDM group vs. SDM group: $p<0.05$} \\
\hline Mean & anda & devi & & & & & & & & & & & & & & & & & & \\
\hline
\end{tabular}

As a result of the analysis, for the question item "3. Effectively conduct an online literature search" and "Ask about needs, values, and treatment preferences", "9. Ask about needs, values, and treatment preferences," and "10. Decide on a course of action,"on the EPIC scale, there were significant differences between the CPG with SDM group, SDM group, and CPG group.

The questionnaire on EBP, for the question item on EBP "11. I learned the foundations for EBP as part of my academic preparation," there were significant differences between the groups and time recognized between the CPG with SDM group and CPG group (CPG with SDM group (mean \pm standard deviation; pre/post): $1.8 \pm 0.8 / 2.2 \pm 1.0$; CPG group: $2.3 \pm 1.1 / 2.0 \pm 1.0$ ) (Table 3). 
Table 3

Evaluation of EBP

\begin{tabular}{|c|c|c|c|c|c|c|c|c|c|c|c|c|c|c|c|c|c|c|c|c|}
\hline \multirow{4}{*}{$\begin{array}{l}\text { Evaluation } \\
\text { of EBP }\end{array}$} & \multirow{3}{*}{$\begin{array}{l}\text { No. } \\
1\end{array}$} & \multicolumn{6}{|c|}{ CPG with SDM Group $(\mathrm{N}=42)$} & \multicolumn{6}{|c|}{ CPG Group ( $N=42)$} & \multicolumn{7}{|c|}{ SDM Group $(N=42)$} \\
\hline & & \multicolumn{3}{|l|}{ Pre } & \multicolumn{3}{|c|}{ Post } & \multicolumn{3}{|l|}{ Pre } & \multicolumn{3}{|c|}{ Post } & \multicolumn{3}{|l|}{ Pre } & \multicolumn{4}{|c|}{ Post } \\
\hline & & 1.8 & \pm & 0.8 & 2.2 & \pm & 1.0 & 2.3 & \pm & 1.1 & 2.0 & \pm & 1.0 & 2.2 & \pm & 0.9 & 2.2 & \pm & 1.0 & * \\
\hline & 2 & 2.3 & \pm & 0.8 & 2.1 & \pm & 0.7 & 2.0 & \pm & 0.9 & 1.9 & \pm & 0.9 & 2.2 & \pm & 0.8 & 2.1 & \pm & 0.9 & \\
\hline & 3 & 2.2 & \pm & 0.7 & 2.5 & \pm & 0.9 & 2.3 & \pm & 1.0 & 2.3 & \pm & 1.1 & 2.3 & \pm & 1.0 & 2.5 & \pm & 1.0 & \\
\hline & 4 & 3.9 & \pm & 0.7 & 3.8 & \pm & 0.8 & 3.9 & \pm & 0.8 & 3.7 & \pm & 0.8 & 3.7 & \pm & 0.7 & 3.8 & \pm & 0.8 & \\
\hline & 5 & 4.1 & \pm & 0.6 & 4.0 & \pm & 0.9 & 4.0 & \pm & 0.8 & 3.9 & \pm & 0.7 & 4.0 & \pm & 0.6 & 4.0 & \pm & 0.7 & \\
\hline & 6 & 2.3 & \pm & 0.7 & 2.3 & \pm & 0.9 & 2.1 & \pm & 0.7 & 2.1 & \pm & 0.7 & 2.1 & \pm & 0.7 & 2.3 & \pm & 0.8 & \\
\hline & 7 & 3.7 & \pm & 0.7 & 3.9 & \pm & 1.0 & 3.7 & \pm & 0.7 & 3.9 & \pm & 0.7 & 3.8 & \pm & 0.7 & 3.9 & \pm & 0.8 & \\
\hline & 8 & 3.8 & \pm & 0.6 & 4.0 & \pm & 0.7 & 3.9 & \pm & 0.7 & 4.1 & \pm & 0.6 & 3.9 & \pm & 0.6 & 4.0 & \pm & 0.7 & \\
\hline & 9 & 2.7 & \pm & 0.7 & 2.8 & \pm & 0.6 & 2.9 & \pm & 0.7 & 2.9 & \pm & 0.6 & 2.7 & \pm & 0.7 & 2.8 & \pm & 0.6 & \\
\hline & 10 & 2.4 & \pm & 0.8 & 2.4 & \pm & 0.8 & 2.6 & \pm & 0.8 & 2.7 & \pm & 0.7 & 2.5 & \pm & 0.8 & 2.4 & \pm & 0.7 & \\
\hline & 11 & 4.0 & \pm & 0.8 & 3.9 & \pm & 0.7 & 3.6 & \pm & 0.7 & 3.9 & \pm & 0.8 & 3.4 & \pm & 0.9 & 3.9 & \pm & 0.9 & \\
\hline & 12 & 3.9 & \pm & 0.6 & 3.9 & \pm & 0.7 & 4.0 & \pm & 0.7 & 3.9 & \pm & 0.8 & 3.6 & \pm & 0.8 & 3.9 & \pm & 0.9 & \\
\hline & 13 & 3.9 & \pm & 0.6 & 3.8 & \pm & 0.6 & 3.5 & \pm & 0.7 & 3.7 & \pm & 0.7 & 3.4 & \pm & 0.9 & 3.8 & \pm & 0.8 & \\
\hline & 14 & 3.9 & \pm & 0.9 & 4.0 & \pm & 0.7 & 3.8 & \pm & 0.7 & 4.0 & \pm & 0.7 & 3.7 & \pm & 0.9 & 4.0 & \pm & 0.8 & \\
\hline & 15 & 3.8 & \pm & 0.9 & 3.9 & \pm & 0.8 & 3.5 & \pm & 1.0 & 3.9 & \pm & 0.7 & 3.5 & \pm & 0.9 & 3.9 & \pm & 0.7 & \\
\hline \multicolumn{21}{|c|}{ SDM: Shared decision making } \\
\hline \multicolumn{21}{|c|}{ CPG: Clinical practice guideline } \\
\hline \multicolumn{21}{|c|}{ * CPG with SDM group vs. CPG group: $p<0.05$} \\
\hline \multicolumn{21}{|c|}{ Mean \pm Standard deviation } \\
\hline \multicolumn{21}{|c|}{ SDM: Shared decision making } \\
\hline CPG: Clinica & actio & guide & & & & & & & & & & & & & & & & & & \\
\hline
\end{tabular}

\section{Discussion}

It became evident that conducting CPG education with SDM education through a workshop style targeting physiotherapists and occupational therapists increased self-efficiency in EBP, compared to having a lecture style of CPG/SDM education. This indicates a new principle for increasing education on self-efficacy in EBP. In order to conduct CPG-related education, SDM education should be concurrently conducted.

In conducting SDM education using CPGs, there are three reasons to improve the confidence of EBP. First is the perspective on "the demand of SDM for CPG," which is stated in the definition of CPG as the significance of the education on communication using SDM. Second is the perspective on "the demand of CPG for SDM," which relates to the requirement of the knowledge of the standard intervention method needed for conducting SDM. Third, as the field of rehabilitation has scarcely assured alternatives and is high in 
uncertainly, having not only the CPG, the core of EBP, but also cooperating with the SDM provides a satisfying sense to physiotherapists and occupational therapists.

Firstly, CPG is defined as: "...a document that presents appropriate recommendations to assist patient and practitioners in making rescissions regarding clinical practice of high importance cased on a body of evidence evaluated and integrated by systematic reviews and the balance between benefits and harms[13]." Fujimoto et al. [33] state that the role of CPG is a communication tool for patients and medical practitioners. Providing education enjoined by the function of CPG in supporting decision-making between patients and medical practitioners as a communication tool could lead to effectual exploitation.

For the nine-step model [25] adopted in this study's SDM education, each step is intended to be a communication tool. In particular, steps 3-6 are built upon identifying patients' preferences and understanding them based on the benefits and risks of the evidence. Understanding this process may have led to an increase in confidence in EBP. In this study, compared to the groups that only had CPG/SDM education, CPG with SDM group increased in the three items on the EPIC scale. These included patients' preferences and understanding steps which correspond to the points in steps 3-6 of the nine-steps about, guaranteeing the hypothesis.

The second point, the perspective on "the demand of CPG for SDM" relates to the requirement of the knowledge of the standard intervention method needed for conducting SDM. In the process of conducting SDM, the knowledge for the applicable treatments and standard evidence for rehabilitation is indispensable for the following steps: "Presentation of treatment options" and "Informing on the benefits and risks of the options."

Contrastingly, it is reported that the consciousness of Japanese therapists on CPGs and the evidence are low compared to foreign countries. Fujimoto et al. [27] researched the consciousness of EBP while targeting Japanese physiotherapists. Although $54.9 \%$ perceived the significance of CPGs, the usage was below 30\% [27], which is way below the $61 \%$ usage in foreign countries [28].

One reason for this could be the lack of therapist education on the usage of CPGs in Japan[27]. In particular, perspectives on applicable situations lack in practical education in Japan [34]. In other words, it is essential to adopt CPGs as a communication technique. As seen in this study, combining CPG education with SDM education leads to the interpretation where the CPG perspective is needed for SDM, which, along with the reason stated above, increased the degree of reliability of EBP.

Thirdly, by conducting CPG education along with SDM education, therapists understood the uncertainty of rehabilitation interventions as well as the availability of SDM in decision-making.

The establishment of evidence is still developing in the field of rehabilitation in Japan. In an earlier study that assessed the quality of practice guidelines of physical therapy released by the Japanese Physical Therapy Association using the AGREE II(Apprisal of

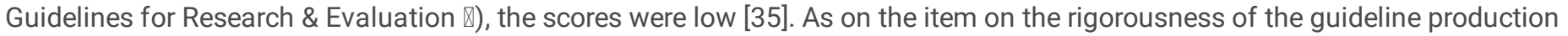
process, such as "Is organized search method is used to search the evidence," the median was 3.0 on a 7-point Likert scale, suggesting the need for modification [35]. Again, the development of a database considering diseases such as cerebrovascular disease, femoral neck fracture, and spinal cord injury is in process to establish evidence on the effectiveness of rehabilitation [36]. However, not enough verification on its effectiveness is managed due to the lack of participating facilities, and further improvements are recommended for the quality of data [36] .

Rehabilitation fields are known for the uncertainty of the treatments due to the high individuality of the goal caused by the various patient factors, such as: physical status, ability of daily living, premorbid life background, home environment. Senior citizens, for instance, who are the main target of rehabilitation, are reported to be challenging to execute a systematic rehabilitation program for because the patients' physical and cognitive functions are disproportional [37,38]. In a field of high uncertainty and having a great number of selections in the treatment, many therapists find it difficult to present evidence to patients [39]. Now, incorporating education on evidence for pre/postgraduate training and communication training on the method in adopting evidence to patients are still unfinished in the current situation [34].

Above all, conducting CPG education with SDM education may convince therapists through experiencing the aspect of communicating and adopting to patients in actual practice that SDM is suitable as a communication tool for decision-making. In fact, in studies targeting foreign physiotherapists, close to half favored SDM for their decision-making approach in the rehabilitation field, with $28.9 \%$ implementing SDM in their clinical practices [40]. SDM is reported to be useful in involving patients in SDM decisionmaking by increasing patients' self-efficacy [41, 42], understanding of the disease and treatments [43, 44], and satisfactions [45, 46].

Page $10 / 15$ 
For this reason, it could be comprehended that SDM is a highly applicable communication tool in the rehabilitation field. In a study that researched the determination of a treatment plan targeting Japanese primary care physicians, $14.6 \%$ practiced SDM, which signifies that SDM has gradually been accepted as a decision-making method in Japan [47].

As above, administering education on evidence with training on communication techniques by instructing the specific steps using the SDM increased confidence toward EBP for therapists, as they were convinced that the utilization of evidence is applicable in clinical situations.

There are three limitations for this study. Firstly, since the "consciousness" of EBP was adopted as a main outcome, it is difficult to reason whether it is practiced in actual clinical situations. As the EPIC scale was used as an index of the self-efficacy of EBP in this study, because it is a self-administered outcome, it is unknown whether the behavior changed in the EBP in the clinical situation or improved patient outcomes. Research on the behavioral change in EBP and improving in patient outcomes when CPGs are used for SDM education is a future subject.

The second is the validity of the subject selection. For the subjects of this study, there is a possibility that the understanding and awareness of SDM/CPG were high, compared to other medical facilities, as this study was carried out in medical facilities where they agreed to cooperate in the research on SDM/CPG. Whether the effectiveness in teaching varied in the difference of the knowledge of SDM/CPG before the intervention has not been examined, which implies that the relationship between the target attribute and the effectiveness cannot be referred to.

Thirdly, there is a possibility of generalization due to limiting the target to Japanese medical facilities. It is reported that Japanese therapists, compared to foreign therapists, are poor in the knowledge of EBP/CPG [6, 10-12]. In contrast to the United States and Australia, Japan is still in the course of development for pre/postgraduate education on EBP/CPG [47]. Hereafter, whether education effectiveness varies due to the difference in curriculum and knowledge needs to be verified.

\section{Conclusions}

EBP education based on the nine-steps of SDM using CPGs increased confidence in EBP for physiotherapists and occupational therapists.

\section{Declarations}

Ethics approval and consent to participate

This study was conducted with the approval of the Ever Walk Inc. Research Ethics Committee (Authorization No.: 002) . Respondents were informed about the project and they provided written consent to participate.

Consent for publication

Not applicable

Availability of data and materials

The datasets used and/or analysed during the current study are available from the corresponding author on reasonable request.

Competing interests

The authors declare they have no competing interests. 
Funding

This study was supported by grants from Japan Primary Care Association. The funding offices had no direct or indirect involvement in the study writeup and analysis, it was only involved in budgeting and budget evaluation.

Authors' contributions

SF contributed to conceptualization, methodology, design and development of the intervention, data collection, data interpretation, the drafting and revising of the manuscript, and was a major contributor in writing the manuscript. TO contributed to the development of the intervention, data collection, and the revising of the manuscript. KK contributed to the statistical analyses, the drafting and revising of the manuscript. TN critically revised the manuscript for important intellectual context. All authors read and approved the final manuscript.

Acknowledgements

Not applicable

\section{References}

1. Guyatt G. Evidence-Based Medicine. JAMA. 1992;268:17.

2. Mickan S, Hilder J, Wenke R, Thomas R. BMC Med Educ. 2019;19(1):131.

3. Farrell B, Archibald D, Pizzola L, Ward N, Cho A, Tsang CFarrell B. Impact on confidence and practice: How the ADAPT online patient care skills program made a difference for pharmacists. Res Social Adm Pharm. 2018;pii: S1551-7411(18)30400-5.

4. Salbach NM, Veinot P, Jaglal SB, Bayley M, Rolfe D. From continuing education to personal digital assistants: what do physical therapists need to support evidence-based practice in stroke management? J Eval Clin Pract. 2011;17(4):786-93.

5. da Silva TM, Costa Lda C, Garcia AN, Costa LO. What do physical therapists think about evidence-based practice? A systematic review. Man Ther. 2015;20(3):388-401.

6. Salbach NM, Guilcher SJ, Jaglal SB, Davis DA. Determinants of research use in clinical decision making among physical therapists providing services post-stroke: a cross-sectional study. Implement Sci. 2010;5:77.

7. Fritz JM, Cleland JA, Brennan GP. Does adherence to the guideline recommendation for active treatments improve the quality of care for patients with acute low back pain delivered by physical therapists? Med Care. 2007;45(10):973-80.

8. Liddle SD, David Baxter G, Gracey JH. Physiotherapists' use of advice and exercise for the management of chronic low back pain: a national survey. Man Ther. 2009;14(2):189-96.

9. Rutten GM, Degen S, Hendriks EJ, Braspenning JC, Harting J, Oostendorp RA. Adherence to clinical practice guidelines for low back pain in physical therapy: do patients benefit? Phys Ther. 2010;90(8):1111-22.

10. Jette DU, Bacon K, Batty C, Carlson M, Ferland A, et al. Evidence-based practice: beliefs, attitudes, knowledge, and behaviors of physical therapists. Phys Ther. 2003;83(9):786-805.

11. Bernhardsson S, Johansson K, Nilsen P, Öberg B, Larsson ME. Determinants of guideline use in primary care physical therapy: a cross-sectional survey of attitudes, knowledge, and behavior. Phys Ther. 2014;94(3):343-54.

12. Fujimoto S, Kon N, Takasugi J, Nakayama T. Attitudes, knowledge and behavior of Japanese physical therapists with regard to evidence-based practice and clinical practice guidelines: a cross-sectional mail survey. J Phys Ther Sci. 2017;29(2):198-208.

13. Fukui T. 2017. https://minds.jcqhc.or.jp/s/guidance_2017_0_h. Accessed 13 Sep 2019.

14. Grimshaw JM, Russell IT. Effect of clinical guidelines on medical practice: a systematic review of rigorous evaluations. Lancet. 1993;342(8883):1317-22.

15. Hoffmann TC, Montori VM, Del Mar C. The connection between evidence-based medicine and shared decision making. JAMA. 2014;312(13):1295-6. 
16. Hoffmann TC, Légaré F, Simmons MB, McNamara K, McCaffery K, et al. Shared decision making: what do clinicians need to know and why should they bother? Med J Aust. 2014;201(1):35-9.

17. Hoffmann TC, Bennett S, Tomsett C, Del Mar C. Brief training of student clinicians in shared decision making: a single-blind randomized controlled trial. J Gen Intern Med. 2014;29(6):844-9.

18. Drake RE, Deegan PE, Rapp C. The promise of shared decision making in mental health. Psychiatr Rehabil J. 2010;34(1):7-13.

19. Adams JR, Drake RE. Shared decision-making and evidence-based practice. Commun Ment Health J. 2006;42(1):87-105.

20. Vranceanu AM, Cooper C, Ring D. Integrating patient values into evidence-based practice: effective communication for shared decision-making. Hand Clin. 2009;25(1):83-96.

21. Giguere A, Légaré F, Grad R, Pluye P, Haynes RB, et al. Decision boxes for clinicians to support evidence-based practice and shared decision making: the user experience. Implement Sci. 2012;7:72.

22. Friesen-Storms JH, Bours GJ, van der Weijden T, Beurskens AJ. Shared decision making in chronic care in the context of evidence based practice in nursing. Int J Nurs Stud. 2015;52(1):393-402.

23. Milner K, O'Connor M. Shared decision making and decision aids: an important part of evidence-based practice. J Nurs Educ. 2017;56(11):702-3.

24. Schulz KF, Altman DG, Moher D. CONSORT. BMJ: updated Guidelines for reporting parallel group randomised trials.BMJ. 2010;23(340):c332.

25. Simon D, Schorr G, Wirtz M, Vodermaier A, Caspari C, et al. Development and first validation of the shared decision-making questionnaire (SDM-Q). Patient Educ Couns. 2006;63(3):319-27.

26. Salbach NM, Jaglal SB, Korner-Bitensky N, Rappolt S, Davis D. Practitioner and organizational barriers to evidence-based practice of physical therapists for people with stroke. Phys Ther. 2007;87(10):1284-303.

27. Fujimoto S, Kon N, Takasugi J, Nakayama T. Attitudes, knowledge and behavior of Japanese physical therapists with regard to evidence-based practice and clinical practice guidelines: a cross-sectional mail survey. J Phys Ther Sci. 2017;29(2):198-208.

28. Bernhardsson S, Johansson K, Nilsen P, Öberg B, Larsson ME. Determinants of guideline use in primary care physical therapy: a cross-sectional survey of attitudes, knowledge, and behavior. Phys Ther. 2014;94(3):343-54.

29. Salbach NM, Guilcher SJ, Jaglal SB, Davis DA. Determinants of research use in clinical decision making among physical therapists providing services post-stroke: a cross-sectional study. Implement Sci. 2010;5:77.

30. Salbach NM, Veinot P, Jaglal SB, Bayley M, Rolfe D. From continuing education to personal digital assistants: what do physical therapists need to support evidence-based practice in stroke management? J Eval Clin Pract. 2011;17(4):786-93.

31. Carter RE, Stoecker J. Descriptors of American Physical Therapy Association physical therapist members' reading of professional publications. Physiother Theor Pract. 2006;22(5):263-78.

32. Yokoyama Y, Kakudate N, Sumida F, Matsumoto Y, Gilbert GH, Gordan VV. Evidence- practice gap for dental sealant application: results from a dental practice-based research network in Japan. Int Dent J. 2016;66(6):330-6.

33. Fujimoto $S$, Kon $N$. The importance of clinical practice guidelines and shared decision-making for supporting the decision-making process of patients and physical therapists. Japanese Journal of Public Health Physical Therapy. 2016;4(1):1-13.

34. Japanese Physical Therapy Association. 2019. http://www.japanpt.or.jp/upload/japanpt/obj/files/about/modelcorecurriculum_2019.pdf. Accessed 13 Sep 2019.

35. Ohtera S, Kanazawa H, Kanazawa N, Kanazawa N, Kinai T, Nakayama T. Appraisal of the first edition of the Japanese guidelines for the physical therapy using the AGREE II Instrument. J Jpn Phys Ther Assoc. 2015;2015(42):596-603.

36. Tokunaga M, Kondo K. Results from the Japan Rehabilitation Database and Future plan. Jpn J Rehabil Med. 2016;53(3):223-7.

37. Huby G, Stewart J, Tierney A, Rogers W. Planning older people's discharge from acute hospital care: linking risk management and patient participation in decision-making. Health Risk Soc. 2004;6(2):115-32.

38. Leach E, Cornwell P, Fleming J, Haines T. Patient centered goal-setting in a subacute rehabilitation setting. Disabil Rehabil. 2010;32(2):159-72.

39. Hofstede SN, van Bodegom-Vos L, Wentink MM, Vleggeert-Lankamp CL, Vliet Vlieland TP, et al. Most important factors for the implementation of shared decision making in sciatica care: ranking among professionals and patients. PLOS ONE.

2014;9(4):e94176. 
40. Topp J, Westenhöfer J, Scholl I, Hahlweg P. Shared decision-making in physical therapy: A cross-sectional study on physiotherapists' knowledge, attitudes and self-reported use. Patient Educ Couns. 2018;101(2):346-51.

41. Causarano N, Platt J, Baxter NN, Bagher S, Jones JM, et al. Pre-consultation educational group intervention to improve shared decision-making for postmastectomy breast reconstruction: a pilot randomized controlled trial. Support Care Cancer. 2015;23(5):1365-75.

42. Durand MA, Carpenter L, Dolan H, Bravo P, Mann M, et al. Do interventions designed to support shared decision-making reduce health inequalities? A systematic review and meta-analysis. PLOS ONE. 2014;9(4):e94670.

43. Branda ME, LeBlanc A, Shah ND, Tiedje K, Ruud K, et al. Shared decision making for patients with type 2 diabetes: a randomized trial in primary care. BMC Health Serv Res. 2013;13:301.

44. Schroy PC 3rd, Emmons K, Peters E, Glick JT, Robinson PA, et al. The impact of a novel computer-based decision aid on shared decision making for colorectal cancer screening: a randomized trial. Med Decis Mak. 2011;31(1):93-107.

45. Fiks AG, Mayne SL, Karavite DJ, Suh A, O'Hara R, et al. Parent-reported outcomes of a shared decision-making portal in asthma: a practice-based RCT. Pediatrics. 2015;135(4):e965-73.

46. Bozic KJ, Belkora J, Chan V, Youm J, Zhou T, et al. Shared decision making in patients with osteoarthritis of the hip and knee: results of a randomized controlled trial. J Bone Joint Surg Am. 2013;95(18):1633-9.

47. Kuga S, Kachi Y, Inoue M, Kawada T. Characteristics of general physicians who practice shared decision making: A mail survey of all clinics in 12 municipalities in Tokyo. An Official Journal Japan Primary Care Association. 2016;39:209-13.

\section{Abbreviations}

AGREE II: Apprisal of Guidelines for Research \& Evaluation 『; CONSORT: Consolidated Standards of Reporting Trials; CPGs: Clinical practice guidelines; EBP: Evidence based practice; EPIC scale: Education, attitudes and beliefs, and interest and perceived role in evidence-based practice; OT: Occupational therapist; PT: Physical therapist; SD: Standard deviation; SDM: Shared decision making; UMIN; University Hospital Medical Information Network center

\section{Figures}




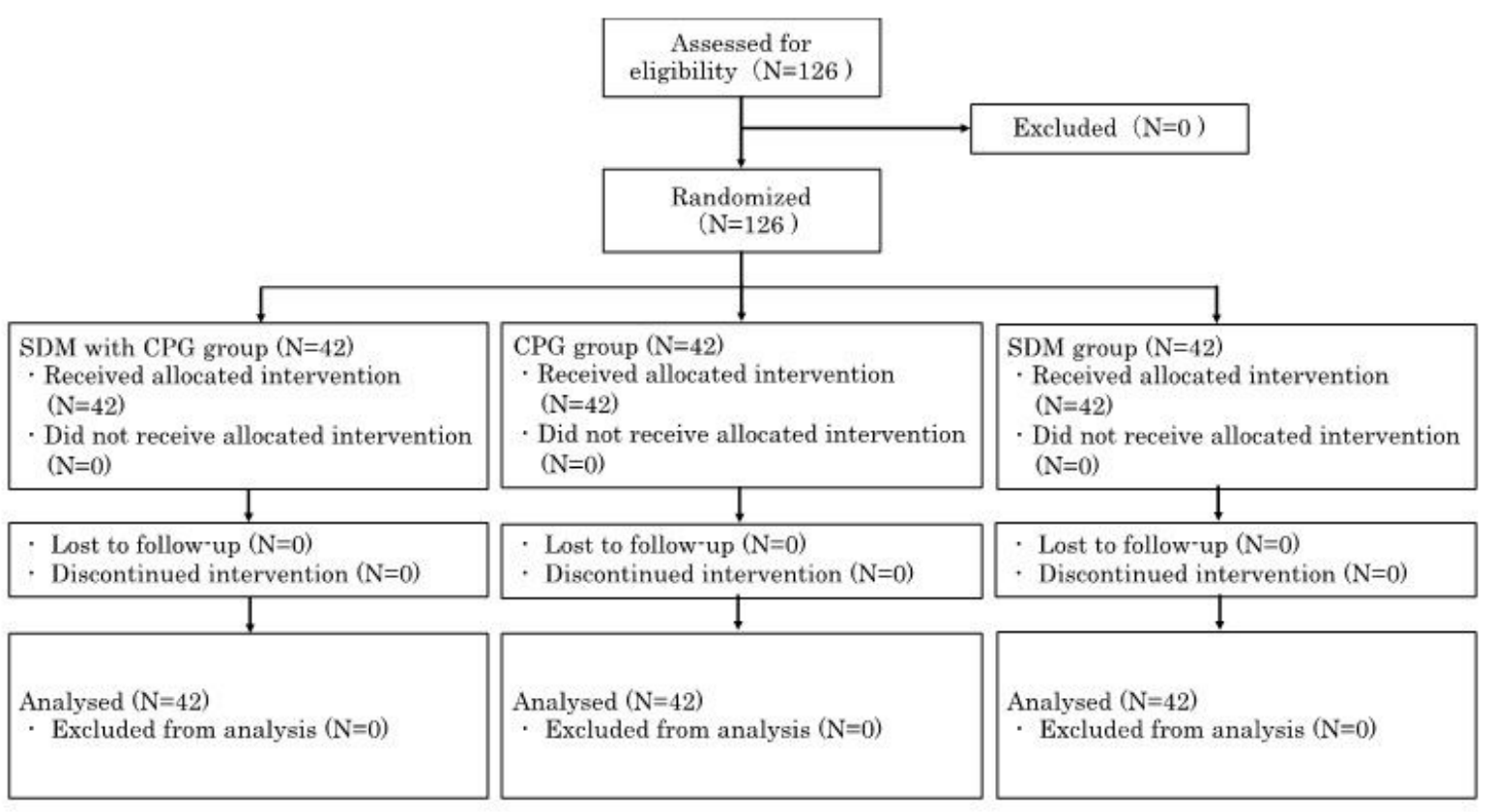

SDM: Shared decision making

CPG: Clinical practice guideline

\section{Figure 1}

Flow Chart

\section{Supplementary Files}

This is a list of supplementary files associated with this preprint. Click to download.

- Additionalfile3CONSORT.doc

- Additionalfile2SDM.docx

- Additionalfile1SDM.docx 